Sajid Alfredo Herrera

\title{
Aproximación filosófica al problema del bien comúnı
}

La pregunta que nos mueve en esta oportunidad es: ¿cómo podría entenderse en nuestra época el bien común? Ella, por supuesto, nos llevará inexorablemente a examinar de manera breve el modo cómo ha sido entendido a través de la historia del pensamiento filosófico. Pero, además, la misma pregunta nos exige cuestionarnos por las posibilidades, límites y alcances de una nación de "bien común" en el mundo de hoy. Una pregunta que nos ata a diversos ámbitos, los cuales son imposible de eludir: lo político, lo ético, lo social, etc. Una pregunta, además, difícil de responder con mucha precisión. Por ello, tendremos que poner a interactuar cuatro conceplos básicos que a nuestro juicio están en la base del problema del "bien común". En unos casos, lo han estado implícitamente en algunas teorías. En otros, se vuelven más palpables. Ellos son la historia, el individuo, la sociedad y la especie. Comencemos, entonces, por descubrir someramente el modo particular e histórico de la noción que nos ocupa a través de dos períodos fundamentales: el mundo clásico y medieval —al que denominaremos siguiendo la terminología de Bobbio- tradición "organicista" y la tradición "individualista" de la modemidad. Posteriomente, queremos ofrecer una sencilla reflexión que partirá de algunas filosofías contemporáneas.

II

En términos generales, y desde el punto de vista filosófico, puede decirse que el mundo clásico y medieval se caracterizó por hipostasear el todo sobre las partes. En esa perspectiva, el concepto de "bien común" quedó sumergido dentro de dicha concepción total u "orgánica". Aristóteles reconoció que el todo era mayor que los fragmentos tanto desde un nivel ontológico como político. Así, la suslancia primera, el motor inmóvil, era mayor que las diversas sustancias particulares. A nivel político, era la ciudad (la polis) la que ostentaba la relevancia 
cronológica y metafísica sobre los individuos, las familias y otras formas de organización social. Fue en la polis en donde, de acuerdo con Aristóteles, los ciudadanos conseguirían obtener la "vida buena": una vida moral y política asumida y gestionada por hombres libres. Serían los ciudadanos los que con su participación colectiva buscarían a través de mecanismos jurídico-políticos el bienestar de todos, porque la polis cra realmente la "comunidad política" por excelencia.

Siguiendo al Estagirita, Tomás de Aquino formuló una visión del bien común denlro de la tradición cristiana, basada en la primacía del todo. Para Tomás, el punto de partida de su razonamiento era Dios como gobernante y legislador del universo. Dado que lodos los hombres participan de las leyes de Dios - por su condición superior de seres racionales-, también éstos requieren leyes humanas para conducir sus actos virtuosamente. Ahora bien, la finalidad de toda ley humana -en tanto se desprenda de la ley natural- será el bien común: ...las leyes son justas según su lin, cuando se ordenan el bien común"2. Se esperará, entonces, que todos los hombres, mientras se guían por las leyes naturales y humanas, tenderán a conseguir el bien común o, al menos, se esperaría esa conducta de quienes gobiernen la ciudad. Para ello, lo gobernantes procurarán no su provecho, sino el bienestar colectivo; de lo conlrario, los súbdilos enconirarán un gobierno tiránico al cual les será lícilo - siempre y cuando no peligre el bien de todos- destituirlos.

Tanto para Aristóteles como para Tomás, el hombre era un ser social por naturaleza. La comunidad de ciudadanos o súbditos procederá de la naturaleza que habría empujado a los hombres a vivir en ámbitos de cooperación y solidaridad. El bien común para el Estagirita tendría, pues, como punto de arranque los mismos dinamismos naturales que le han exigido a los hombres su convivencia con otros. De igual forma, para Tomás, el bienestar común tendría su punto de arranque en la esencia social del hombre tal como Dios lo había creado. Sin embargo, mientras el mundo clásico y medieval sobredimensionó el todo frente a las partes; el mundo modemo, la modemidad, configuró un paradigma metafísico, antropológico y sociopolítico distinto.

Se ha dicho - y con mucha razón- que la modernidad y todos sus proyectos se fundamentaron en una concepción individualista. Habrá, entonces, que preguntamos desde este proyecto moderno cómo se entendió el bien común. Esta pregunta con su respectiva respuesta resulta muy significaliva desde el hecho que somos deudores todavía de la modernidad; por lo que el presupuesto básico bajo el cual gravitará la noción de bien común en ellos no nos será del todo desconocida. Basta que veamos la concepción contractualista para poder ilustramos. De acuerdo con los contractualistas modernos - Hobbes, Locke, Kant, entre otros- las partes son anteriores al todo. Son los individuos los que, cronológica y ontológicamente, poseen la primacía sobre el todo social. Los 
individuos no son seres sociales por naturaleza —aunque en el estado natural de Locke hayan indicios de cooperación social一; más bien, sus derechos y razón natural son los que guían sus acciones, procurando no entorpecer los derechos de los demás. $Y$ aunque se vuelva inevitable la agresión, mientras no haya un acuerdo común, la fuente de autoridad residirá en cada uno de los sujetos. Pero para evitar una catástrofe, los individuos deciden conformar una unión de voluntades, una sociedad civil, que a los ojos del contractualismo moderno no fue más que un atomismo social, una agregación, una sumatoria de voluntades individuales. El bien común consistió, entonces, en el resultado de la sumatoria de los bienes particulares.

La ilustración en cuanto madurez de la modemidad enfatizó en este individualismo ético de raigambre religiosa y filosófica. A su juicio, el bien social se encontraba radicado en el bien de cada una de las partes que integraban la totalidad. Ha sido el utilitarismo la corriente filosófica ilustrada que proporcionó a los individuos tanto su autonomía como su desarrollo personal bajo la búsqueda de la felicidad. Dicho principio puede verse tanto en Bentham como en John Stuart Mill. Sobre el mismo, Mill sostenía que: "en proporción al desenvolvimiento de su individualidad, cada persona adquiere un mayor valor para sí mismo y es capaz, por consiguiente, de adquirir un mayor valor para los demás. Se da una mayor plenitud de vida en su propia existencia y cuando hay más vida en las unidades hay también más en la masa que se compone de ellas"'. A pesar de ello, no toda la época ilustrada fue un crisol de tesis individualistas. Rousseau fue quizá el pensador de la época de las luces más conocido quien denunció románticamente las desigualdades sociales que acarreaba la propiedad privada bajo el paradigma individualista.

III

Luego de haber hecho un breve recorrido a los dos "modelos" anteriores - si se nos permite esa acepcion- en tomo al bien común, nos queda pendiente una interrogante principal: ¿podremos aproximarnos filosóficamente a una concepluación que logre superar dichos modelos? El intento es necesario. Pero su necesidad no lo convierte en la absolutización de un nuevo "modelo" ni mucho menos en la restricción de otras alternativas teóricas. Si bien en la tradición organicista hay una fundamentación de carácter global del bienestar colectivo que a todas luces parece aceptable, este espejismo global conduce a graves inconvenientes. Cuando Aristóteles afirmaba que en la polis, como un todo político y moral, los ciudadanos obtendrán la "vida buena", los alcances de esta vida buena exigían la condición de ciudadanía a sus beneficiarios. El resto de la población no se incluía. Por otra parte y desde una perspectiva metafísica, la sustancialización de la polis resulta, después de la crisis o "muerte" del sujeto, un obstáculo para repensar nuestro problema. Es necesario y urgente construir una altemativa "total" o global del bien común, no excluyente ni basada en los 
desaciertos de la metafísica occidental.

En un primer momento hay que decir que el bien común es un hecho historico y como tal deberá tenérsele en cuenta. No en vano, filósofos como Ellacuría pedían una "historización" del bien común en nuestras sociedades contempóraneas. Y es que de lo contrario, aceptar su ahistoricidad nos podría llevar a aceplar el planteamiento del contractualismo y su hipótesis sobre los individuos en su "condición natural", con las consecuencias antisociales que conlleva tal propuesta. En cualquier caso, la historicidad del bien común desmiente su tratamiento como una entidad abstracta e inmulable y al mismo tiempo desmiente su tratamiento exclusivo a ciertos pueblos, grupos o naciones. Algunos planteamientos de los neocontractualismos propenden a esta situación. El caso de John Rawls es paradigmático al respecto, sobre todo cuando establece que la caracterización de los bienes primarios para una sociedad no se hará en base a averiguar las circunstancias históricas de ésta —dado que se parte de una "posición original" y que se toma como modelo una sociedad democrática-, sino en base a una concepción de la persona dada de antemano4.

Como hecho histórico, el bien común se ha presentado como un ideal buscado permanentemente; como un punto referencial bajo el cual las distintas formas sociales han pretendido conseguir su bienestar. Primero, se ha entendido como un bienestar de un "grupo" étnico que constituía la ciudad o la comunidad política. La ilustración lo asumió como el bienestar de los individuos que en último término se reducía a los nuevos grupos sociales en ascenso. En la actualidad son las naciones, las etnias, los hombres y las mujeres, los trabajadores, los que demandaban mejores condiciones de vida. Por ello, la historia del bien común ha sido la historia misma de la búsqueda de mayor dignidad y respeto de las personas y los pueblos.

En un segundo momento debemos sostener que no es posible conceptualizar el bien común sin tomar en cuenta la relación individuo-sociedad, pero sin primar uno en detrimento del otro. Dicho en otras palabras, evitando caer en colectivismos homogenizadores $\mathrm{ni}$ en individualismos insolidarios. Si consideramos que dicha relación configura una "condelerminación", es decir, una mutua interdependencia no habría necesidad de diluir una realidad con respeclo a la segunda. La sociedad no es un marcro-agregado de individuos que un día dispusieron establecer sus vínculos sociales. La sociedad no ha sido un construclo elaborado por los hombres sin que estos hayan sido moldeados por ella. En este punto, Zubiri aporta elementos valiosos para la comprensión de la relación codeterminante individuo-sociedad. Según Zubiri, antes que nosotros vayamos al encuentro de los demás, éstos ya han entrado e intervenido en nosotros. Son los otros lo que van configurando e imprimiendo una vida en los sujetos. Es la sociedad la que previamente se ha hecho presente en los individuos. De ahí que el individualismo modemo e ilustrado que concebia filosóficamente a los sujetos 
autónomos de todo nexo social no tiene ya sentido. "La realidad humana -dice Zubiri- no es puramente mi propia realidad, es una realidad que desborda la realidad mía. Y, precisamente, la realidad humana está formando parte de mi realidad y está configurando mi realidad humana"s.

Por otra parte, lo social al configurar a los individuos no impide la realización de sus peculiaridades. Hablar de sociedad no tiene porqué llevamos a concebirla como un proceso de homogenización. No es así. Cada sujeto es único. Por lo que a la relación inicial individuo-sociedad se une un tercer elemento indispensable en la clarificación de nuestro problema: es la especie. De hecho, la sociedad se funda en la especie como realidad física. La especie, el phylum humano, al que aludimos difiere de ser un mero concepto clasificatorio. Es una base físico-biológica, real, de donde procedemos todos a través de la generación de vida que realizan nuestros progenitores. Si bien es cierto que cada individuo engendrado recibe o le es "comunicado" un "esquema constilutivo" -es decir, unos elementos físico-biológicos comunes a lodos los humanos que le hacen pertenecer al mismo phylum-, no por eso ha perdido sus peculiaridades. Cada humano es a la vez "uno y común"t. Esta condición de particularidad y comunidad refuerza lo dicho anteriormente que, por una parte, no hay un detrimento del individuo sobre la sociedad y viceversa; y por otra, que la sociedad no es un proceso homogenizador a pesar de la existencia de un "esquema constitutivo" que todos compartimos. En este sentido, cualquier visión masificadora que pudiera desprenderse del principio organicista - "el todo es mayor que las partes"- quedaría en franca discusión.

\section{IV}

Una vez vista rápidamente la unidad entre historia-individuo-sociedad-especie en orden a una conceptuación aclual del bien común, nos queda por articular dichos elementos. Ya hemos dicho que el bien común no puede reducirse a un simple concepto que anularía su riqueza histórico-concreta. El bien común es y ha sido una aspiración histórica, un ideal buscado por los individuos y las colectividades que si bien puede estar vinculado a un plano religioso, no es un bien o unos bienes que dependan de "otro mundo" o que están en función incondicional de lo "trascendente", tal como creía Tomás de Aquino. Una concepción de esa naturaleza refuerza lo que bien Nielzsche sostenía: un miedo o terror a esta vida. En ese sentido, la tradición marxista proporcionó una incuestionable valoración de las condiciones materiales bajo las cuales los individuos se van haciendo y construyendo (praxis) los procesos históricos. Pues bien, la historicidad del bien común no resulta ajeno a Ia tríada individuo-sociedad-especie. Todo lo contrario, la historicidad tanto de los humanos como de sus organizaciones sociales pende de ese sustrato físico que es el phylum humano. Por tanto, hablaremos de bienestar o de bienes comunes a todos los individuos pertenecientes a la especie humana. 
No obstante, la historicidad de la cual hablamos no es un proceso del devenir racional (arte, filosofía, ciencias, etc.) tal como apuntaba la conocida metafísica hegeliana. Otra vez nos serviremos del pensamiento zubiriano para acercamos a una noción de historia no como proceso de héroes o del pensamiento, sino como dinamismo de posibilidades. Las diversas posibilidades que la realidad natural o social le ha presentado a los individuos y la apropiación de aquéllas por éstos a través de los tiempos es lo que básicamente puede concebirse desde la perspectiva zubiriana como "historia". Claro está que dicha concepción filosófica tiene un componente epistemológico fundante que no considera a los hombres ni primaria ni primeramente unos "animales racionales", tal como lo había hecho la tradición filosófica occidental. Más bien, los ha considerado como "animales de realidades" y que por motivos de espacio no entraremos en este punto propio de una filosofía del conocimiento. Basta con señalar su importancia.

La historia es "transmisión tradente", es decir, transmisión de formas de estar en la realidad con las cuales los individuos podrán hacer su vida y transformar las relaciones humanas y naturales. Por tanto, aparece aquí la opción humana como un ingrediente que habilita a los sujetos escoger su vida ante las distintas posibilidades con las cuales se enfrenta. A partir de lo anterior, podría pensarse el hecho de la historia como un hecho cifrado en clave individualista: los hombres y mujeres como afectados y ejecutores de su realidad y de la realidad de otros. Sin embargo, Zubiri es claro en este punto: el sujeto de la historia es el phylum humano mismo en cuanto cuerpo social, no los sujetos por separado o una nación en particular. Y esto por una sencilla razón: los sujetos humanos tomados en su individualidad son momentos constitutivos del sistema social. La sociedad sería de esta manera una unidad estructural de individuos que se encuentran "codeterminados" en mutua interdependencia, unos con otros. La clave de lectura es, enlonces, distinta. Es una clave que se declara desde un principio como "común" y que posibilita la "comunidad histórica de la humanidad".

La discusión reciente entre la filosofía de la liberación y la ética del discurso -personaificada en Dussel y Apel- tiene el mérito de haber puesto en la mesa del debate el terna de los excluidos (países del sur, tercer mundo) de aquellos bienes primarios de los cuales goza un porcentaje muy pequeño de la población mundial. Sin embargo, a la base del lenguaje o del discurso se encuentra ese sustrato biológico —s decir, la especie- que no debemos perder de vista. Una aproximación filosófica al problema del bien común que desee superar los proyectos organicistas de la antigüedad y del medioevo, así como los proyectos individualistas de la modernidad, deberá considerar ese componente natural. La pertenencia de todos los hombres, mujeres, etnias, culturas, naciones al mismo phylum humano no es simplemente una noción. Es una constatación de la cual no escapa evidencia alguna. Es cierto que cada individuo es "único" e irrepetible; lo mismo puede decirse de las etnias y culturas con sus propias lenguas, costum- 
bres o creencias. Pero también es cierto que si todas las personas proceden del mismo phylum humano, todas poseen algo "común" que les ha sido comunicado por procesos genéticos. Ese "algo común" que une las diferencias existentes nos sirve a nosotros para evidenciar que los bienes a los cuales tienen derecho todas las personas (vida, salud, alimentación, educación, seguridad...) no son privativos de algunas socicdades o individuos en perjuicio de otros que son los más. De ahí que no basta entonces la participación en el diálogo norte-sur o la crítica a la exclusión que sufren los países tercermundistas en esc diálogo para fundamentar sin más una ética de la responsabilidad solidaria. Creemos que la "comunidad histórica humana" que surge por medio de la comunidad phylética es un elemento fundante del bien común. La "comunidad dialógica" de la ética del discurso descansaría, pues, en dicha comunidad phylética.

\section{V}

En el actual estado de cosas, cuando la palabra de moda o el cliché es la globalización, cabe preguntarse si es posible una "globalización del bien común". El papel de la filosofía es el de ofrecer propuestas teóricas que sirvan en la discusión de los problemas sociales. En ese caso, queda fuera de la filosofía ofrecer estrategias encaminadas al cómo deberán operativizarse las distintas alternativas elegidas. Ese sería el papel de la economía, la política o las ciencias sociales. La tarea de la filosofía sigue siendo una tarea potenciadora de la reflexión crítica del "mundo de la vida". Desde esa perspectiva, la pregunta por la posibilidad del bien común en una sociedad globalizada o, que al menos, se enseñorea por su mundialización, no resulta ociosa. Como hemos visto, mientras no haya en nuestros espacios vitales mundializados una realización concreta del bienestar para las grandes porciones de la humanidad, la globalidad de recursos y posibilidades que ofrecerían mejores condiciones de vida, quedaría concentrado siempre en las naciones que defienden su propia expansión socioeconómica y cultural. Sin embargo, una vez que hemos llegado a este punto se hace necesario detenernos para aclarar cómo entendemos esta "globalización del bienestar humano". No se trata de realizar una utopía al estilo renacentista, en donde el principal rector sea el "igualitarismo". Un principio por lo demás ideal y romántico. Sobre este asunto en particular es muy sugerente lo que ha escrito Norberto Bobbio.

Según Bobbio, los hombres son tan iguales como desiguales en muchos aspeclos - recuérdese que sobre este punto ya tenemos un antecedente teórico desde la perspectiva zubiriana. Bajo esa evidencia empírica irrefutable, tal como sosticne este pensador italiano, es necesario diferenciar una concepción "igualitarista" de una concepción "igualitaria". Esta última estimará que es posible reducir, aminorar o eliminar las desigualdades sociales y convertir en menos penosas las desigualdades naturales. En cambio, una posición igualitarista sostendría la igualdad de lodos en todo ${ }^{\sharp}$. Bobbio cita como ejemplos de los logros 
alcanzados por los "igualitarios" la lucha por los derechos sociales tales como el derecho a la educación a la salud y al trabajo. "Las tres - sostiene Bobbiotienden a hacer menos grande la desigualdad entre quien tiene y quien no tiene, o a poner un número de individuos siempre mayor en condiciones de ser menos desiguales respecto a individuos más afortunados por nacimiento y condición social"'.

Una concepción de bien común en nuestra época rnundializada y posmodema requiere tener en cuenta el principio igualitario del cual Bobbio se convierte en su partidario. ¿Por qué? En primer lugar, es cierto que se demanda la efectivización de derechos en la población mundial; sin embargo, no todos los hombres somos iguales en todo. Aunque procedamos del mismo phylum humano, las diferencias singulares y colectivas son palpables tal como indicamos arriba. Algunas técnicas, recursos y bienes que occidente o los países industriales consideran como indispensables para el bienestar social no son aptos para otros pueblos y por ello su mundialización sería nociva. La comunidad histórica que formamos todos los seres humanos muestra así la diversidad y riqueza que ella misma contiene, porque no es una comunidad metafísica al estilo leibniziano o según Berkeley. Es una comunidad de hombres y mujeres concretos que conservan sus diferencias étnicoculturales por la misma "transmisión tradente". Cada pueblo se ha apropiado de sus posibilidades y ha transmilido formas de vida de distinla manera a otros. Por lo que pretender una homogeneización (llámese igualitarismo), sin respetar el pluralismo sociocultural, bajo el pretexto de posibilitar universalmente el "bien común" sería un grave error. Sobre ello, el pensador mexicano, Pedro de Velasco, ha escrilo: "en la actual globalización no se da un acceso universal a los diversos bienes propios de cada cultural, tampoco su conocimiento y aprecio de dichos bienes, ni una potenciación de su producción. El intento se reduce a globalizar unos cuanlos bienes producidos en serie (...). Por otro lado, ni siquiera hay una verdadera universalización del acceso a estos bienes...". Un bien común mundializado es que la población mundial sepa leer y escribir. Sin embargo, no es un bien común si se obliga a las poblaciones indígenas, por ejemplo, que abandonen su lengua a cosla de aprender una lengua extraña a ellos. Un bien común mundializado es el derecho al trabajo para todos; sin embargo, se distorsiona si se implantan esquemas laborales occidentales a naciones que poseen, dentro de sus cosmovisiones, un rilmo propio de trabajo.

En segundo lugar, debemos tener en cuenta el principio igualitario por el cual simpatiza Bobbio, porque nos hace caer en la cuenta que las desigualdades sociales no están determinadas naturalmente, sino, por el contrario, son efeclo de las acciones mismas de los hombres. Por lo mismo, propenden a ser solucionadas por los mismos hombres. Como ya apuntamos, la historia de la humanidad es un dinamismo de apropiación de posibilidades. Los hombres se enfrentan a su realidad natural y social, se hacen cargo de ella. En esa apropiación de posibilidades ellos tienen la capacidad de elegir entre unas y otras; o bien, pueden 
modificar y transformar sus vidas y las de los demás. El inconveniente del modelo aristotélico que veíamos al inicio era precisamente su fundamento biológico que apuntaba a ciertos deterninismos. La polis griega como actualización de potencias reclama una interpretación de innegable naturalismo, dado que los gémenes de dicha comunidad política se encontraban de antemano en las primeras organizaciones sociales. Básicamente este determinismo social ha sido cuestionado duramente por las filosofías post-hegelianas como el marxismo. No obstante, la consideración de la vida como práctica humana" no es suficiente sino se tiene en cuenta el ámbito de la solidaridad. La visión de praxis es importante porque se enfrenta a una idea de humanidad atadas a sus problemas sociales y sin encontrar ninguna solución a ellos por el supuesto carácter natural de aquéllos. Pero, nada garantiza o ha garantizado que dicha praxis sea verdaderamente humanizante. Por lo que la "responsabilidad solidaria" (término utilizado por algunos filósofos) se vuelve en un referente obligado en estas consideraciones.

El bien común como "bienestar comunicable", es decir, como biencstar transmitible a todos, se sigue enfrentando lamentablemente a la encrucijada entre praxis versus determinismo natural. Las posturas triunfalistas -deudoras del optimismo ilustrado - del final de la historia conlinúan apelando al hecho étnicocultural como raíz de los problemas sociales en regiones no desarrolladas. Dicha raíz étnico-cultural la interpretan en claves naturales, o en otras palabras, pertenece a la esencia misma de lales regiones su atraso socioeconómico, por lo que no es posible ir contra natura. Así lo afirma Fukuyama: "la cultural, los hábitos, costumbres, religiones, estrucluras sociales de los pueblos como América Latina obstruyen, de alguna manera, el logro de altos niveles cconómicos"12. Partiendo de ese razonamiento miope, se vuelve necesario como urgente una reformulación actual del bien común mundializado que respete las diferencias o divcrsidades de la comunidad humana, pero también que considere a dicha comunidad como una praxis con responsabilidad solidaria. Por el contrario, mientras los problemas sociales mundiales o nacionales como el desempleo, la pobreza, el analfabetismo, entre olros, escapen de análisis inlegrales y, a la vez, escapen de acciones conducentes a la optimización de la calidad de vida de la población mundial o nacional, seguiremos teniendo posturas lan simplistas pero también tan legitimadoras del actual estado de cosas.

La filosofía contemporánea, sobre todo las filosofias de la intersubjectividad, al impugnar el modelo antropológico individualista de raigambre moderna han proporcionado una perspectiva teórica recuperable en tomo a la solidaridad humana. Frente al sujeto libre (prolotipo del individualismo liberal, de la ética, metafísica y epistemología modema) se ha propuesto un ser humano responsable de los otros ${ }^{13}$. La responsabilidad solidaria y la solidaridad equitativa permitirán un bien común comunicable a grandes porciones de la humanidad. Tal vez con- 
venga no denominar al bien común como un "bien globalizable" dado el significado profundo al que propende el término "globalización" (exclusión, imposición de bienes y valores occidentales que no siempre son los mejores o más convenientes para otros pueblos, etc.). A lo mejor sería más adecuado hablar en estos liempos de una "comunización" no es nuestra, remite a considerar a la humanidad como una comunidad diversa que continuará exigiendo la realización efectiva de sus derechos.

\section{Nolas}

1. Texto de la comunicación presenıada en la Conferencia sobre el "Bien común" en el Colegio de Altos Estudios Estratégicos (11 de febrero 1998).

2. Tratado de la ley, I, II, c. 96, 4 en Tomás de Aquino, Tratado de la ley. Tratado de la justicia. Opúsculo sobre el gobierno de los príncipes, México, Edit. Porrúa, 1975.

3. Sluar Mill, J. Sobre la libertad, Madrid, Alianza, 1994, p. 135.

4. Rawls, J. Sobre las libertades, Barcelona, Paidós, 1990, pp. 51-52.

5. Zubiri, X. Sobre el hombre, Madrid, Alianza, 1986, pp. 233ss.

6. Zubiri, $X$. Siete ensayos de antropología filosófica, Bogotá, Universidad Santo Tomás, 1982, pp. 27-54.

7. Ibid., pp. 130 ss.

8. Bobbio, N. Derecha e izquierda. Razones y significados de una distinción política, Madrid, Taurus, 1995, p. 140ss. También puede verse del mismo aulor: Igualdad y liberıad, Barcelona, Paidós, 1993, pp. 83-89.

9. Ibíd., p. 151.

10. Velasco, P. "La sociedad del futuro entre la cocina y la fragua. Del melting-pot a las cazuelas de mole" en AA.VV., Mundialización y liberación. II Encuentro Mesoamericano de Filosofia, Managua, UCA, 1996, p. 183.

11. Marx, K. Los manuscritos de 1844 y las tesis sobre Feuerbach. San Salvador, UCA Editores, 1988, p. 144.

12. Cilado en Rojas, M. "La mundialización y la necesidad de re-construcción de la identidad cultural”, en A^.VV., Mundialización y liberación... p. 165.

13. Ver Beorlegui, C. "El pensamiento ético-antropológico de E. Lévinas. Su fecundidad y sus insuficiencias" (mimco), p. 5-6. 